\title{
Montreal's contribution to the Quebec anesthesia workforce: a comparison between anesthesia residents trained at McGill University and those trained at Université de Montréal La contribution de Montréal aux effectifs québécois en anesthésiologie: une comparaison entre les résidents formés à l'Université McGill et ceux formés à l'Université de Montréal
}

\author{
Andrew M. Suess, MD • Anne Lavoie, MD • \\ Pierre Drolet, MD · José A. Correa, PhD • \\ Steven B. Backman, MDCM, PhD
}

Received: 12 August 2011/Accepted: 16 January 2012/Published online: 10 February 2012

(C) Canadian Anesthesiologists' Society 2012

\begin{abstract}
Purpose Alumni from McGill University (MAA) and alumni from Université de Montréal (UMA) anesthesia residency programs were compared with regard to demographic characteristics and practice location.
\end{abstract}

This article is accompanied by an editorial, please see Can J Anesth 2012; 59(4).

\begin{abstract}
Author contributions Steven B. Backman conceived of the project and supervised data collection, analysis and preparation of the figures, and wording of the manuscript. Andrew M. Suess was the McGill anesthesia resident who collected the McGill data, analyzed the results, and helped with all aspects of data analysis and preparation of the figures. He also helped with preparation of the text. Pierre Drolet helped to design the study and supervised the data collection and analysis. He also participated in writing the manuscript. Anne Lavoie was the Université de Montréal anesthesia resident who collected the Université de Montréal data, analyzed the results, and helped with data interpretation and preparation of the figures. She also helped with preparation of the text. José A. Correa was the statistician who helped with all aspects of data analysis, statistical testing, and interpretation of our findings. He also helped with preparation of the manuscript.
\end{abstract}

A. M. Suess, MD · S. B. Backman, MDCM, PhD ( $\square)$

Department of Anesthesia, Royal Victoria Hospital, McGill

University, F9.08, 687 Pine Ave. W., Montreal, QC H3A 1A1,

Canada

e-mail: steven.backman@muhc.mcgill.ca

\section{A. Lavoie, MD - P. Drolet, MD}

Département d'anesthésiologie, Université de Montréal,

Montreal, QC, Canada

J. A. Correa, $\mathrm{PhD}$

Department of Mathematics and Statistics, McGill University,

Montreal, QC, Canada
Methods McGill University alumni and UMA (1990-2010) were studied according to age, sex, pre-anesthesia education, fellowship training, advanced research training, and practice location. Logistic regression analysis of demographics in relation to practice location was performed.

Results Alumni were mostly male (MAA [ $n=102]$; male:female 72 [71\%]: 30 [29\%] vs UMA [ $n=89$ ]; male:female 51 [57\%]: 38 [43\%]) in their early thirties [mean 32; standard deviation (3.2) and 32 (3.0), respectively]. Approximately $45 \%$ of MAA obtained an undergraduate education in provinces other than Quebec compared with 6\% of UMA. A majority of alumni from either institution practice in Quebec (MAA 67\%; UMA 94\%). Of the MAA who received undergraduate education in Quebec, approximately $80 \%$ practice in that province compared with approximately $46 \%$ of those who were educated in other provinces. Fellowship training for MAA who work in Quebec or in other provinces was similar (68\%). About one-third (33\%) of UMA who work in Quebec obtained fellowship training. All alumni who received undergraduate education abroad (MAA $n=9$; UMA $n=1)$ practice in Quebec. Three MAA and one UMA practice in the USA. Regression analysis suggests that working in Quebec is associated with obtaining an undergraduate medical education in that province (odds ratio 4.3; 95\% confidence interval 1.1 to 21.2).

Conclusions The majority of MAA and UMA practice in Quebec, particularly if they received their undergraduate education there. Residents educated (undergraduate) in the rest of Canada are more likely to practice in other provinces. Residents with undergraduate education from abroad are highly likely to practice anesthesia in Quebec. A small portion of alumni elect to practice anesthesia in the USA. 


\section{Résumé}

Objectif Les diplômés des programmes de résidence en anesthésiologie de l'Université McGill (MAA) et de l'Université de Montréal (UMA) ont été comparés en termes de caractéristiques démographiques et de lieu d'exercice de la profession.

Méthodes Les diplômés de l'UniversitéMcGill et les UMA (1990-2010) ont été étudiés en fonction de leur âge, sexe, formation pré-anesthésiologie, formation postdoctorale, formation avancée en recherche et lieu d'exercice. Une analyse de régression logistique des caractéristiques démographiques par rapport au lieu d'exercice a été effectuée.

Résultats Les diplômés étaient surtout des hommes (MAA [ $n=102]$; ratio homme/femme: 72 [71 \%] / 30 [29\%] contre UMA [ $n=89]$; ratio hommelfemme: 51 [57\%] / 38 [43\%]) dont l'âge se situait dans le début de la trentaine (moyenne [écart-type]: 32 ans [3,2] et 32 ans [3,0], respectivement). Approximativement $45 \%$ des MAA ont fait leurs études de médecine dans une province autre que le Québec, contre $6 \%$ des UMA. La majorité des diplômés des deux universités exercent au Québec (MAA 67 \%; UMA $94 \%$ ). Parmi les MAA ayant fait leurs études de médecine au Québec, environ $80 \%$ pratiquent dans la province, comparés à environ $46 \%$ de ceux qui avaient fait leurs études dans d'autres provinces. La proportion de formation postdoctorale chez les MAA travaillant au Québec ou dans les autres provinces est semblable (68\%). Environ un tiers (33\%) des UMA travaillant au Québec ont obtenu une formation postdoctorale. Tous les diplômés qui ont étudié la médecine à l'étranger (MAA, $n=9$; UMA, $n=1$ ) exercent au Québec. Trois MAA et un UMA exercent aux États-Unis. L'analyse de régression logistique suggère que travailler au Québec est associé au suivi d'études médicales dans cette province (rapport de cotes: 4,3; intervalle de confiance à $95 \%: 1,1$ à 21,2).

Conclusions La majoritédes MAA et des UMA exercent au Québec, notamment s'ils y ont fait leurs études médicales. Les résidents formés (premier cycle) dans le reste du Canada sont davantage susceptibles d'exercer dans d'autres provinces. Les résidents ayant fait leurs études de médecine à l'étranger sont très susceptibles d'exercer en anesthésiologie au Québec. Enfin, un petit nombre de diplômés choisit de pratiquer l'anesthésiologie aux États-Unis.

When planning manpower needs for any given region, it is crucial to understand the likelihood that anesthesia residents graduating from a given program will remain in the province where they trained, as they comprise a natural pool to supply licensed healthcare providers. Recently, the Association des Anesthésiologistes du Quebec attempted to predict provincial anesthesia human resource requirements and assumed that virtually all of the anesthesiology residents graduating from Quebec university programs of French heritage remain in the province. ${ }^{\mathrm{A}}$ However, it was unable to make any estimation concerning the anesthesia residents graduating from McGill University. McGill University has the only Faculty of Medicine in the Province of Quebec where the training is predominantly in English, and its anesthesia residency program, contrary to the other anesthesia training programs in Quebec, accepts a significant number of residents from outside the province. Understandably, these residents may have weaker personal reasons to remain in Quebec upon completion of their training. In this regard, it is relevant to recognize McGill University's acknowledged mix of national and international students and its reputation for supplying the USA with the largest percentage of physicians graduating from a medical school in Canada. ${ }^{1}$

There is scant literature regarding where Canadiantrained anesthesia residents practice following completion of training. Data from a 1996 national survey of anesthesiologists and residents suggest that approximately $80 \%$ of those educated in Quebec continue to work there after completion of their training. However, the university training centres were not differentiated, and the results were based on only a $58 \%$ response rate. ${ }^{2}$ The location of two culturally distinct universities in Montreal (i.e., McGill University of Anglo heritage and Université de Montréal of French heritage) with their respective faculties of medicine offers a unique opportunity to compare anesthesia residents graduating from each institution. We sought to determine the demographic characteristics of the anesthesia residents in each program and whether they are associated with practicing in Quebec after residency completion. As such, we sought to determine the contribution of Fellows of The Royal College of Physicians of Canada (FRCPC)-certified anesthesiologists from McGill University and Université de Montréal to the anesthesia workforce in Quebec, the remainder of Canada, and beyond and to identify factors that may influence this contribution.

\section{Methods}

With Ethics Boards approval (MUHC Study Code 11-606Gen), we report a retrospective analysis of McGill University anesthesia alumni (MAA) and Université de Montréal anesthesia alumni (UMA) spanning a period from 1990-2010. Information regarding MAA was retrieved from an institutional departmental alumni database which is updated on an annual basis. Since no such database exists

\footnotetext{
${ }^{\text {A }}$ Trepannier $C$. President AAQ, personal communication.
} 
at the Université de Montréal, UMA were identified from physician databases provided by the Association des Anesthésiologistes du Québec and the Fédération des Médecins Résidents du Québec. A questionnaire requesting the same information found in the McGill database was sent by E-mail to UMA and a second E-mail was sent if there was no reply. Finally, non-responders were contacted by phone. McGill's database and Université de Montréal's questionnaire provided the following demographic information: name, sex, date of birth, location of undergraduate non-medical education, location of undergraduate medical education, date of graduation from residency training, postresidency fellowship training, advanced research training (Master's of Science or Doctor of Philosophy), and current practice location. We did not seek information regarding sequential practice locations following completion of training. Additionally, we distinguished Quebec-educated alumni who obtained a Diplôme d'études collégiales (DEC) at a collège d'enseignement général et professionnel (CEGEP) with only one year of undergraduate non-medical education (no bachelor's degree) from those who obtained a bachelor's degree (with or without a DEC) prior to commencing undergraduate medical education.

Descriptive statistics for both MAA and UMA were obtained for sex, age at graduation, location of undergraduate non-medical education, location of undergraduate medical education, completion of a DEC without a bachelor's degree, fellowship training completion, advanced research training completion, and current practice location.

To compare mean age at graduation between MAA and UMA as well as between MAA who practice in Quebec $v s$ outside Quebec after training completion, we used Student's $t$ tests for independent samples. To compare proportions by sex, location of undergraduate non-medical education (Quebec vs non-Quebec), location of undergraduate medical education (Quebec vs non-Quebec), completion of a DEC without a bachelor's degree, fellowship training, advanced research, and current practice location (Quebec vs non-Quebec), we used the Chi square tests for comparisons on cross-classification tables. However, when at least one cell in a cross-classification table had an expected value $<5$, we used the Fisher's exact test.

To investigate the association between current practice location and demographic factors, we performed a multiple logistic regression analysis. The dependent variable of interest, i.e., current practice location, and the main independent variables, i.e., location of undergraduate medical and non-medical studies, were dichotomized as Quebec and non-Quebec. Age at graduation was modelled as a continuous variable. Completion of a DEC without a bachelor's degree, fellowship training, and advanced research training were considered binary (Yes, No). The assumption of linearity in the logit for the continuous variable, age at graduation, was assessed by the BoxTidwell test. ${ }^{3}$ Multicollinearity was assessed using the Pearson correlation coefficient statistic and by checking the Variance Inflation Factor on a multiple regression model with the same dependent and independent variables. ${ }^{4}$ The log-likelihood ratio test was used to test the overall significance of the model. The significance of the variables in the model was assessed by the Wald Chi square test, and the fit of the model was assessed by the Hosmer-Lemeshow goodness-of-fit Chi square test. ${ }^{5}$ In order to assess outliers and detect influential observations, logistic regression diagnostics were performed by plotting several diagnostic statistics against the predicted values using estimated values and Pearson and deviance residuals. The logistic regression analysis was done on the MAA only (an insufficient number of UMA working outside of Quebec precluded such analysis of this cohort).

All analyses were done using SAS ${ }^{\circledR}$, version 9.2 (SAS Institute Inc., Cary, NC, USA). Data are presented as number (\%) or mean (standard deviation). All statistical hypothesis tests were two-sided and performed at the 0.05 significance level.

\section{Results}

\section{McGill University alumni}

One hundred and eight alumni graduating from the McGill Department of Anesthesia were identified. Six of these were from the Middle East and came to McGill University for anesthesia residency training with the sole intention of returning home afterwards. As such, they were excluded from further analysis. Most of the remaining 102 alumni were male $(n=72)$, and the average age at graduation was $32 \mathrm{yr}$ (Table 1). Twenty-four of the 102 MAA had only a DEC (no bachelor's degree), 54 obtained their undergraduate non-medical degree, and 55 obtained their medical education in Quebec. Forty-six MAA received their undergraduate medical and/or non-medical education in provinces other than Quebec, and nine were educated abroad. Nine had an advanced research degree, and 69 obtained fellowship training after completion of residency.

Sixty-eight of the 102 MAA (67\%) work in Quebec (Tables 2, 3). Most of the MAA working in Quebec obtained their undergraduate education in Quebec: 42/68 trainees with undergraduate non-medical education (42/54 [78\%] MAA with this education [Tables 1, 2]); 45/68 trainees with undergraduate medical education (45/55 [82\%] MAA with this education [Tables 1, 2]). Nineteen of 68 MAA working in Quebec obtained a DEC (19/24 [79\%] MAA with this education [Tables 1, 2]). Twenty-one of 68 MAA working in Quebec obtained their undergraduate 
Table 1 Demographic data of MAA and UMA

\begin{tabular}{lllr}
\hline & MAA $(n=102)$ & UMA $(n=89)$ & $P$ Value \\
\hline Age Grad (yr) & $32.0(3.2)$ & $32.0(3.0)$ & 0.5 \\
M/F & $72(71 \%) / 30(29 \%)$ & $51(57 \%) / 38(43 \%)$ & 0.06 \\
DEC & $24(24 \%)$ & $40(45 \%)$ & 0.002 \\
Undergrad Non-Med Ed QC & $54(53 \%)$ & $84(94 \%)$ & $<0.0001$ \\
Undergrad Med Ed QC & $55(54 \%)$ & $88(99 \%)$ & $<0.0001$ \\
Undergrad ROC (Non-Med/Med) & $46(45 \%)$ & $5(6 \%)$ & 0.0001 \\
Educated Abroad (Non-Med/Med) & $9(9 \%)$ & $1(1 \%)$ & 0.02 \\
Fellowship & $69(68 \%)$ & $31(35 \%)$ & $7(8 \%)$ \\
Advanced research degree & $9(9 \%)$ & 0.0001 \\
\hline
\end{tabular}

Data is presented as mean (standard deviation) or $n(\%)$. MAA = McGill University anesthesia alumni; UMA = Université de Montréal anesthesia alumni; $\mathrm{DEC}=$ Diplôme d'études collégiales; $\mathrm{QC}=$ Quebec; $\mathrm{ROC}=$ rest of Canada

Table 2 Demographics of MAA practicing in and outside of QC following completion of residency training

\begin{tabular}{llll}
\hline & $\begin{array}{l}\text { MAA in } Q C \\
(n=68)\end{array}$ & $\begin{array}{l}\text { MAA Outside } Q C \\
(n=34)\end{array}$ \\
\hline Age Grad $(y r)$ & $32.3(3.6)$ & $31.3(2.1)$ & 0.1 \\
M/F & $49 / 19$ & $23 / 11$ & 0.6 \\
UGrad Non-Med Ed QC & $42(62 \%)$ & $12(35 \%)$ & 0.01 \\
UGrad Med Ed QC & $45(66 \%)$ & $10(29 \%)$ & 0.0004 \\
DEC & $19(28 \%)$ & $5(15 \%)$ & 0.14 \\
Undergrad ROC & $21(31 \%)$ & $25(74 \%)$ & 0.0001 \\
Educated Abroad (Non-Med/Med) & $9(13 \%)$ & $2(6 \%)$ & 0.03 \\
Advanced research degree & $7(10 \%)$ & $23(68 \%)$ & 0.7 \\
Fellowship & $46(68 \%)$ & 1.0 \\
\hline
\end{tabular}

Data is presented as mean (standard deviation) or $n(\%)$. MAA $=$ McGill University anesthesia alumni; QC $=$ Quebec; DEC $=$ Diplôme d'études collégiales; $\mathrm{ROC}=$ rest of Canada

Table 3 Practice location of MAA and UMA following completion of residency training

\begin{tabular}{lcl}
\hline & MAA $(n=102)$ & UMA $(n=89)$ \\
\hline Quebec & $68(67 \%)$ & $84(94 \%)$ \\
Ontario & $17(17 \%)$ & 0 \\
Alberta & $5(5 \%)$ & 0 \\
British Columbia & $4(4 \%)$ & $2(2 \%)$ \\
Manitoba & $1(1 \%)$ & 0 \\
Saskatchewan & $1(1 \%)$ & 0 \\
New Brunswick & $1(1 \%)$ & $2(2 \%)$ \\
Nova Scotia & $1(1 \%)$ & 0 \\
Saudi Arabia & $1(1 \%)$ & 0 \\
USA & $3(3 \%)$ & $1(1 \%)$ \\
\hline
\end{tabular}

MAA $=$ McGill University anesthesia alumni; UMA = Université de Montréal anesthesia alumni

education (medical or non-medical) in provinces other than Quebec (21/46 [46\%] MAA with this education [Tables 1, 2]). The location of undergraduate non-medical and medical education for MAA and the likelihood of practicing in Quebec following completion of residency training are summarized in Tables 4 and 5, respectively. Seven of 68 MAA practicing in Quebec held advanced research degrees (7/9 [78\%] MAA with this training [Tables 1, 2]). All nine of the MAA educated abroad practice in Quebec upon completion of residency training, and 46/68 MAA practicing in Quebec completed fellowship training (46/69 [67\%] MAA with this education [Tables 1, 2]).

Almost all of the MAA working outside of Quebec $(n=34)$ remained in Canada $(n=30)$ with the majority in Ontario $(n=17)$. Three of these MAA work in the USA (Tables 2,3). Twelve of the MAA working outside of Quebec completed undergraduate non-medical education within Quebec, ten completed their medical education within Quebec, and five completed a DEC. Twenty-five of the 34 MAA working outside of Quebec received their undergraduate education in provinces other than Quebec. Two trainees had advanced research degrees and 23 
Table 4 Location of undergraduate non-medical education and likelihood of practicing in Quebec following completion of residency training

\begin{tabular}{lcl}
\hline $\begin{array}{l}\text { Location Non-Med } \\
\text { Undergrad Education }\end{array}$ & MAA in QC & UMA in QC \\
\hline Quebec & $42 / 54(78 \%)$ & $80 / 83(96 \%)$ \\
Ontario & $8 / 16(50 \%)$ & $2 / 3(66 \%)$ \\
Alberta & $1 / 5(20 \%)$ & - \\
British Columbia & $3 / 6(50 \%)$ & - \\
Manitoba & $2 / 4(50 \%)$ & - \\
Saskatchewan & $2 / 3(66 \%)$ & - \\
New Brunswick & $1 / 3(33 \%)$ & $1 / 2(50 \%)$ \\
Nova Scotia & $0 / 2(0 \%)$ & - \\
USA & $4 / 4(100 \%)$ & - \\
Columbia & $2 / 2(100 \%)$ & - \\
Brazil & $1 / 1(100 \%)$ & - \\
England & $1 / 1(100 \%)$ & - \\
USSR & $1 / 1(100 \%)$ & - \\
Cuba & - & $1 / 1(100 \%)$ \\
\hline
\end{tabular}

MAA $=$ McGill University anesthesia alumni; UMA = Université de Montréal anesthesia alumni; QC = Quebec

Table 5 Location of undergraduate medical education and likelihood of practicing in Quebec following completion of residency training

\begin{tabular}{lcl}
\hline Location Med Undergrad Ed & MAA in QC & UMA in QC \\
\hline Quebec & $45 / 55(82 \%)$ & $83 / 88(94 \%)$ \\
Ontario & $6 / 17(35 \%)$ & - \\
Alberta & $3 / 7(43 \%)$ & - \\
British Columbia & $2 / 5(40 \%)$ & - \\
Manitoba & $2 / 5(40 \%)$ & - \\
Saskatchewan & $2 / 3(66 \%)$ & - \\
Nova Scotia & $1 / 3(0 \%)$ & - \\
USA & $2 / 2(100 \%)$ & - \\
Columbia & $2 / 2(100 \%)$ & - \\
Brazil & $1 / 1(100 \%)$ & - \\
France & $1 / 1(100 \%)$ & - \\
USSR & $1 / 1(100 \%)$ & - \\
Cuba & - & $1 / 1(100 \%)$
\end{tabular}

MAA = McGill University anesthesia alumni; UMA = Université de Montréal anesthesia alumni; QC $=$ Quebec

obtained additional fellowship training following anesthesia residency (Table 2).

Table 6 shows the maximum likelihood estimates for the logistic regression analysis using the MAA data. Due to sparseness of the data concerning the variables fellowship, advanced degree, and DEC, we used exact logistic regression for the estimation regression parameters. ${ }^{5} \mathrm{We}$ found that, in the presence of the other covariates of interest, obtaining an undergraduate medical education in
Quebec is associated with working in Quebec after residency, with significantly higher odds for those who obtained the degree in Quebec compared with those outside of Quebec (odds ratio 4.3; 95\% confidence interval 1.1 to 21.2).

\section{University of Montreal alumni}

One hundred four alumni who graduated from the Université de Montréal anesthesia residency program were identified; 15 of these were excluded from further analysis because of incomplete data. The remaining 89 UMA were mostly male (51 male/38 female), and the average age at graduation was $32 \mathrm{yr}$ (Table 1$)$. The vast majority of UMA received their undergraduate non-medical $(n=84)$ or medical $(n=88)$ education in Quebec. Forty UMA had a DEC (no bachelor's degree). Only five UMA received an undergraduate education in provinces other than Quebec, and one was educated abroad. Seven UMA had an advanced research degree, and 31 obtained fellowship training after completion of residency.

Eighty-four of the 89 UMA work in Quebec (Tables 3, 7). Of the UMA who received either undergraduate nonmedical or medical education in Quebec, 81/84 (96\%) and 83/88 (94\%), respectively, practice in Quebec (Tables 1, 7). Of those UMA who received an undergraduate education in provinces other than Quebec, $3 / 5(60 \%)$ practice in Quebec. The only UMA with undergraduate education abroad continued to work in Quebec after residency training.

Most of the UMA working outside of Quebec $(n=5)$ remained in Canada, with only one working in the USA (Tables 3, 7). A majority completed undergraduate nonmedical (3/5) or medical (5/5) education in Quebec, and two of these completed a DEC without a bachelor's degree. Most completed fellowship training $(n=3)$, but none held an advanced research degree.

\section{Discussion}

This study examined alumni from McGill University and Université de Montréal who received Royal College certification in anesthesia during a 20-year period. We determined the demographic characteristics of the anesthesia residents in each program and whether they were associated with practicing in Quebec after residency completion. We noticed a number of similarities between each group. A similar number of anesthesia residents were trained in each program; graduates were in their early thirties, and males outnumbered females. Most residents from either program obtained their undergraduate training in Quebec, and a small percentage of residents had 
Table 6 Maximum likelihood estimates of exact logistic regression model for MAA $(n=102)$

\begin{tabular}{llllrr}
\hline Variable & $\begin{array}{l}\text { Estimated Regression } \\
\text { Coefficient }\end{array}$ & $\begin{array}{l}\text { Standard } \\
\text { Error }\end{array}$ & P Value & Estimated OR & 95\% CI for OR \\
\hline Sex (F / M) & -0.24 & 0.48 & 0.8 & 0.8 & 0.3 \\
Age at Graduation*** & 0.14 & 0.09 & 0.1 & 1.2 & 2.3 \\
Undergrad Non-Med Ed (QC / non-QC) & 0.11 & 0.63 & 1.0 & 1.1 & 0.9 \\
Undergrad Med Ed (QC / non-QC) & 1.46 & 0.65 & 0.04 & 4.3 & 0.3 \\
DEC (Y / N) & 0.05 & 0.75 & 1.0 & 1.1 & 1.1 \\
Fellowship (Y /N) & -0.01 & 0.48 & 1.0 & 1.0 & 0.2 \\
Advanced research degree (Y / N) & -0.17 & 0.96 & 1.0 & 0.8 & 0.3 \\
\hline
\end{tabular}

The number of events $(n=68$, [work in QC]) and non-events $(n=34$ [work outside QC]). The overall significance of the model by the loglikelihood ratio test was $16.3(P=0.02)$ with $7^{\circ}$ of freedom $(\mathrm{df})$. No significant interaction effects were found. No potential outliers were detected, and the continuous variable age at graduation met the linearity assumption for logistic regression analysis. $* * *$ Odds ratio (OR) for oneyear difference in age at graduation is indicated. For three-year difference, OR $=1.5$; $95 \%$ confidence interval (CI) 0.9 to 2.7 ; five-year difference $\mathrm{OR}=2.0 ; 95 \% \mathrm{CI} 0.9$ to 5.4 . QC $=$ Quebec; $\mathrm{DEC}=$ Diplôme d'études collégiales

Table 7 Demographics of UMA practicing in and outside of QC after completion of residency training

UMA = Université de Montréal anesthesia alumni;

$\mathrm{QC}=$ Quebec; $\mathrm{ROC}=$ rest of Canada; $\mathrm{DEC}=$ Diplôme

d'études collégiales

\begin{tabular}{lll}
\hline & $\begin{array}{l}\text { UMA in QC } \\
(\mathrm{n}=84)\end{array}$ & $\begin{array}{l}\text { UMA outside QC } \\
(\mathrm{n}=5)\end{array}$ \\
\hline Age Grad (yr) & $31.7(3.0)$ & $31.0(2.4)$ \\
M/F & $49 / 35$ & $2 / 3$ \\
Undergrad Non-Med Ed QC & $81(96 \%)$ & $3(60 \%)$ \\
Undergrad Med Ed QC & $83(99 \%)$ & $5(100 \%)$ \\
DEC & $38(45 \%)$ & $2(40 \%)$ \\
Undergrad ROC & $3(4 \%)$ & $2(40 \%)$ \\
Educated abroad (Non-Med/Med) & $1(1 \%)$ & 0 \\
Advanced research degree & $7(8 \%)$ & 0 \\
Fellowship & $28(33 \%)$ & $3(60 \%)$ \\
\hline
\end{tabular}

advanced research degrees. A majority of alumni from either institution chose to practice in Quebec upon completion of residency training, and in the cohorts who obtained their undergraduate education abroad, all practice in Quebec after residency. A very small percentage of anesthesia residents graduating from either program practice in the USA.

The striking difference between MAA and UMA is the relatively greater percentage of MAA who received their undergraduate education in provinces other than Quebec. Of central interest to this study, $67 \%$ of MAA work in Quebec compared with $94 \%$ of UMA. When MAA are differentiated into Quebec- and rest of Canada-educated (undergraduate medical or non-medical) groups, approximately $80 \%$ and $46 \%$, respectively, practice in Quebec following residency training. Logistic regression analysis of the MAA cohort indicates that working in Quebec was associated only with obtaining an undergraduate medical education in Quebec.

We acknowledge the inability to identify the "home" province of any given resident accurately, in contrast to identifying the province of origin, which is relatively easy to determine. Individuals may be born in one province and subsequently obtain their education in different provinces within Canada. First degree relatives, too, may have undergone parallel or divergent moves, further obscuring the definition of "home". Be that as it may, if the assumption is made that the majority of residents who received their undergraduate education in Quebec are likely "Quebecers" and those educated outside of Quebec are most probably "non-Quebecers", then a conclusion can be drawn from this study that upon completion of anesthesia residency training, Quebec anesthesiologists graduating from McGill University are 1.7 times more likely to remain in Quebec than their non-Quebec counterparts. A further conclusion can be drawn that MAA constitute a more heterogeneous population with regard to province of origin compared with their UMA counterparts.

This study provides only a current snapshot of MAA and UMA practice location and does not account for the possibility of sequential moves after completion of training. We acknowledge that movement of practice location 
within the province of Quebec can and does occur, but we are convinced that there has been relatively little migration of anesthesiologists to and from this province over the 20-year period of study.

The observation that all MAA and UMA who obtained their undergraduate education abroad remain in Quebec to practice is significant. This may partially reflect service contracts variably applied during the last 20 years which stipulate that these trainees work in Quebec for a defined period of time.

The objective of the logistic regression analysis was to investigate the association between current practice location and demographic factors of interest. Although the effective sample size (i.e., the minimum of the number of events or non-events) is 34 , our model contained seven independent variables. Since this is a for-hypothesis-testing model, all covariates of interest, whether significant or not, were included in the model, which allows for more accurate $P$ values for tests for the variable of interest. ${ }^{6}$ However, the estimates resulting from this model may not be suitable for estimation of effects or for prediction of practice location from the variables included in the model.

Management of healthcare manpower to ensure the optimal functioning of each hospital department is a challenging and dynamic process. Available literature indicates that Canada is in the midst of an anesthesia workforce shortage that is predicted to worsen with time. ${ }^{7,8}$ Yet, current and predicted manpower requirements at Canadian university hospital departments of anesthesia via informal inquiry ${ }^{\mathrm{B}}$ contradict these conclusions, suggesting that our understanding of the supply and demand balance of anesthesiologists in Canada may be limited. The results from this study provide information concerning the supply of anesthesiologists trained at two university programs in Montreal. These results confirm the widely held notion that almost all residents graduating from Université de Montréal remain in Quebec to practice. Moreover, they reassure that the McGill University anesthesia residency program contributes a considerable number of trained specialists who remain in the province of Quebec. Importantly, the vast majority of MAA who leave Quebec remain in Canada $v s$ the considerable number of graduates from the McGill University School of Medicine who practice in the USA (see introduction).

The findings from this study must be interpreted in the unique social and political contexts of Quebec life. This province consists of about 7.5 million people who claim French (80\%), English (8\%), and other (12\%) languages as their mother tongue. ${ }^{9}$ McGill University, of Anglo heritage, has the only Faculty of Medicine in the Province of

\footnotetext{
B Association of Canadian Departments of Anesthesia (ACUDA) Winter Meeting, Toronto, 8 January 2011.
}

Quebec where the training is predominantly in English, and so it is no surprise that it has relatively more students originating from outside the province than the Université de Montréal (and certainly the two other Quebec university medical programs). Moreover, until 2006, medical students applying to the francophone residency programs did so outside of the Canadian Resident Matching Service (CaRMS), instead applying through a parallel Quebec resident matching program (which excluded McGill University). It is beyond the scope of this discussion to weigh the benefits of having a diverse pool of residents competitively selected from across Canada vs the cost of losing a portion of these trainees once they graduate with their specialty fellowship certification. In fact, considering that most Quebec-based practitioners have traditionally earned less money than their counterparts in the rest of Canada, it is somewhat surprising that so many trainees remain in this province to work. For residents graduating from Quebec francophone institutions, a long-held view is that an English work environment is a major disincentive to seek employment outside of Quebec. However, the findings from the present study suggest that even those comfortable working in a predominantly English environment prefer to work in Quebec. It is our opinion that superior working conditions for anesthesiologists in Quebec provided by the anesthesia respiratory therapists have played a major role in recruiting and retaining Quebec-trained residents. However, a serious threat to the continued recruitment of our best and brightest trainees is the strict limitation of available positions imposed by the Quebec Ministry of Health and, in particular, the inability to share positions as full-time equivalent (FTE) employees. This inflexible approach makes it virtually impossible to offer a position unless faced with a vacancy created by retirement, relocation, etc. It is hoped that those in the Quebec Ministry of Health can adopt a more flexible attitude that will facilitate thoughtful proactive manpower planning in accordance with the healthcare, educational, and research needs of the province. It would be a spectacular waste of human resources to have a cadre of highly skilled healthcare professionals, educated in Quebec and unable to find employment in their own province.

In conclusion, this study of anesthesia residents graduating from two Montreal-based institutions, McGill University and Universite de Montréal, demonstrates that the majority choose to practice in Quebec, particularly if they had received their undergraduate education in that province. However, residents who receive their undergraduate education outside of Quebec are more likely to practice in other provinces following completion of residency training. All residents with undergraduate education obtained abroad remain in Quebec to practice anesthesia after residency completion. Only a very small portion of 
alumni from either institution practice anesthesia in the USA.

Acknowledgements We gratefully acknowledge Ms D. MacFarlane's assistance with retrieving the information concerning the anesthesia residents graduating from the McGill University Department of Anesthesia.

Funding This project was funded entirely from department sources.

Conflicts of interest None declared.

\section{References}

1. Phillips RL Jr, Petterson S, Fryer GE Jr, Rosser W. The Canadian contribution to the US physician workforce. CMAJ 2007; 176: $1083-7$.
2. Donen N, King F, Reid D, Blackstock D. Canadian anesthesia physician resources: 1996 and beyond. Can J Anesth 1999; 46: 962-9.

3. Box GEP, Tidwell $P W$. Transformation of the independent variables. Technometrics 1962; 4: 531-50.

4. Allison PD. Logistic Regression Using the SAS $\odot$ System: Theory and Application. Cary, NC: SAS Institute, Inc.; 1999 .

5. Hosmer DW, Lemeshow S. Applied Logistic Regression. 2nd ed. New York, NY: John Wiley and Sons, Inc.; 2000.

6. Harrel FE Jr. Regression Modeling Strategies with Applications to Linear Models, Logistic Regresssion and Survival Analysis. NY: Springer; 2001.

7. Craig D, Byrick R, Carli F. A physician workforce planning model applied to Canadian anesthesiology: planning the future supply of anesthesiologists. Can J Anesth 2002; 49: 671-7.

8. Byrick RJ, Craig D, Carli F. A physician workforce planning model applied to Canadian anesthesiology: assessment of needs. Can J Anesth 2002; 49: 663-70.

9. Statistics Canada. Available from URL: www.statcan.gc.ca (accessed December 2011). 